Research letter

\title{
New drug resistance mutations of reverse transcriptase Human immunodeficiency virus type-1 gene in first-line antiretroviral-infected patients in West Sumatra, Indonesia
}

\author{
Efrida Efrida ${ }^{1}$, Ellyza Nasrul ${ }^{1}$, Ida Parwati ${ }^{2}$, Jamsari Jamsari ${ }^{1}$ \\ ${ }^{1}$ Andalas University, Padang, West Sumatera, Indonesia \\ ${ }^{2}$ Padjadjaran University, Bandung, West Java, Indonesia
}

Received 11 January 2018, Accepted 5 April 2018

(C) 2018, Efrida E., Nasrul E., Parwati I., Jamsari J.

(C) 2018, Russian Open Medical Journal

Abstract: Background - Antiretroviral (ARV) therapy has successfully reduced the transmission, morbidity, and mortality of Human immunodeficiency virus 1 (HIV-1) infection, but the appearance of drug resistance mutations (DRMs) is an obstacle to successful HIV management. DRMs against nucleoside reverse transcriptase inhibitors (NRTIs) and non-nucleoside reverse transcriptase inhibitors (NNRTIs) have never been analyzed and reported in HIV-1 patients in Padang (West Sumatra, Indonesia).

Objective - This study aimed to identify NRTI- and NNRTI-DRMs from HIV-1 proviral deoxyribonucleic acid (DNA) in HIV-infected patients who had received ARV therapy for $>12$ months at the Dr. M. Djamil General Hospital in Padang.

Material and Methods - We isolated HIV-1 proviral DNA from blood samples from 105 HIV-1 patients who had undergone first-line ARV therapy for $>12$ months. Isolates were amplified via a nested PCR technique using two primer-specific types of reverse transcriptase (RT). The amplicon was electrophoresed on $0.8 \%$ agarose gel and then sequenced. Analysis of DRMs in the HIV-1 RT genes was based on the Standford HIV database.

Results - The 17 isolates from 105 ARV-treated patients, eight RT genes were successfully sequenced, and DRM of RT inhibitors was found in one of the isolates (12.5\%). The Stanford HIV database analysis detected three new DRMs at the 184th, 215th and 190th codon positions, causing three mutations: M184L and T215N (NRTI-DRMs) with low-level resistance to zidovudine, and G190D (NNRTI-DRM).

Conclusion - We concluded that the new DRMs found in Padang, West Sumatra indicates the importance of genotypic resistance testing and the periodic evaluation of the effectiveness of ARV drugs currently in use.

Keywords: Human immunodeficiency virus, antiretroviral therapy, drug resistance mutation

Cite as Efrida E, Nasrul E, Parwati I, Jamsari J. New drug resistance mutations of reverse transcriptase Human immunodeficiency virus type-1 gene in first-line antiretroviral-infected patients in West Sumatra, Indonesia. Russian Open Medical Journal 2018; 7: e0207.

Correspondence to Efrida Efrida. E-mail: efridasppk@yahoo.com

\section{Introduction}

The provision of highly active antiretroviral treatment (HAART) may decrease the transmission, morbidity, and mortality of Human immunodeficiency virus 1 (HIV-1) infection due to its ability to suppress the virus to undetectable levels. Long-term use of HAART, however, leads to drug-selective immune pressure in the HIV-1 population. This selective pressure causes mutations of the viral peptide as it attempts to escape the host immune system. The virus that escapes the immune system is a mutant strain that possesses better replication and viral fitness capacity, which may lead to the accumulation of mutations [1]

The accumulation of mutations during targeted therapy has led to the emergence of drug resistance mutations (DRMs). DRMs are suspected to cause treatment failure and immune system reconstitution failure, allowing the disease to progress rapidly $[2,3]$.

Information concerning DRM in Indonesia is very limited, and DRMs have not been analyzed and reported in people with HIV-1 in Padang, West Sumatra, Indonesia. The study by Khairunnisa et al. [3] in Surabaya reported that 53 reverse transcriptases (RT) sequences from $66 \mathrm{HIV}$-infected persons who had received HAART for more than two years identified a major DRM genetic strain of $37.7 \%(20 / 53)$. This high prevalence of DRM is a marker of the need for periodic evaluation of the effectiveness of HAART use in Indonesia.

The number of HIV cases in Indonesia tripled between 2001 and 2009, and the virus is now found in all provinces in Indonesia (in 2004, it was only reported in 11 provinces). Cumulatively between 1 April 1987 and 30 September 2014, there were 150,296 HIV-positive cases, 55,799 cases of acquired immune deficiency syndrome (AIDS), and 9,796 HIV-related deaths. This prevalence is likely to be greater due to the large number of HIV/AIDS sufferers who do not report themselves [4].

The Indonesian provinces with the highest prevalence of AIDS cases per 100,000 people are Papua $(359.43 / 100,000)$, West Papua $(228.03 / 100,000)$, Bali $(109.52 / 100,000)$, and DKI Jakarta $(77.82 / 100,000)$. West Sumatra is ranked $14^{\text {th }}$, with a prevalence $19.64 / 100,000$ [4]. Based on data from the Ministry of Health Republic of Indonesia in 2015, there were 1,136 HIV patients in 
West Sumatra as of September 2014. Padang City has the second highest prevalence of HIV/AIDS after Bukittinggi.

The increased number of HIV cases in Indonesia led to the government's launch of the HAART expansion program in 2004. The first-line antiretroviral (ARV) typically recommended in Indonesia is a combination of two nucleoside reverse transcriptase inhibitor (NRTI) groups and a non-nucleoside reverse transcriptase inhibitor (NNRTI) group. NRTI-class ARVs include zidovudine (AZT), tenofovir (TDF), lamivudine (3TC), and emtricitabine (FTC), whereas NNRTI-class ARVs are nevirapine (NVP) and efavirenz (EFV). A combination of protease inhibitors (PPIs) with lopinavir/ritonavir (LPV/r) and two classes of NRTIs is the secondline ARV recommended for people with HIV who manifest virological failure or toxicity to NNRTIs [5].

Based on the background described above, this study aimed to detect DRM in HIV-1 patients aged $>18$ years who had been using first-line HAART for more than one year at the Dr. M. Djamil General Hospital in Padang, West Sumatra. The present study was the first study in West Sumatra to identify DRM against HAART.

\section{Material and Methods}

\section{Demographic characteristics of the research subjects}

Demographic characteristics were obtained from the patients' medical records. A total of 105 HIV-1 patients aged $>18$ years who had received first-line HAART for more than 12 months had blood drawn by trained phlebotomists at Poli Voluntary Counseling Testing.

\section{Isolation of HIV-1 proviral deoxyribonucleic acid}

After blood samples were obtained from HIV patients, HIV-1 proviral deoxyribonucleic acid (DNA) was extracted from $2 \mathrm{~mL}$ whole blood in ethylenediaminetetraacetate and the number of CD4 T-cells was examined in the Central Laboratory at the Dr. M. Djamil General Hospital in Padang. Extraction was conducted using the genome Purelink DNA kit (Invitrogen). The work procedure was in accordance with the recommended protocols of the kit, consisting of 1) blood thinning, 2) DNA binding, 3) DNA leaching, and 4) DNA elution. The extraction results were electrophoresed to ensure the success of the isolation procedure.

\section{Amplification via nested polymerase chain reaction technique}

Amplification was performed on the RT gene, via two stages of amplification. In Stage, I, the DNA template of HIV-1 DNA was proviral DNA. The primers used were HIV-RT1-R (5'-GGA CTA CAG TCY ACT TGT CCA TG-3') and HIV-RT1-F (5'-ATG ATA GGG ATG GGA ATG GGT TT-3'), which was added to a PCR master Mix (Invitrogen). Amplification was performed over 30 cycles of polymerase chain reaction (PCR), with each cycle consisting of initial denaturation at $92^{\circ} \mathrm{C}$ for 10 minutes, further denaturation at $92^{\circ} \mathrm{C}$ for 30 minutes, annealing at $55^{\circ} \mathrm{C}$ for 30 minutes, extension at $72^{\circ} \mathrm{C}$ for 45 minutes, and further extension at $72^{\circ} \mathrm{C}$ for 5 minutes. In Stage II, the template DNA was the PCR product from Stage I, the primers used were HIV-RT2-R (5'-TTA AAA TCA CTA RCC ATT GYT CTC C-3') and HIV-RT2-F (5'-GAC CTA CAC CTG TCA ACA TAA TTG G-3'), and the same PCR master mix (Invitrogen) was used. Amplification was conducted for 30 cycles using the same PCR settings are those used in Stage I.

\section{Electrophoresis of $P C R$ products}

Electrophoresis of nested PCR products was performed using a $0.8 \%$ agarose gel and cyber green colorant. Electrophoresis was set to 100 volts for 40 minutes, and results were measured using UV light.

\section{Sequencing and DRM analysis}

Sequencing was conducted at 1st Base Singapore. The sequencing results were analyzed to identify mutations and amino acid changes in the RT gene. The sequence was aligned with CLUSTAL-W software version 1.81 and edited using BioEdit sequence editor version 7.0.4. The type and position of mutations and amino acid changes were determined by comparison to a reference sequence. The sequence was uploaded to the Stanford University HIV Drug Resistance Database to obtain a DRM profile.

\section{Results}

A total of 80 research subjects $(76.2 \%)$ were men, $48.6 \%$ were aged $30-39$ years and $52.4 \%$ were married (Table 1 ). The highest level of education of the respondents was high school or equivalent $(50.5 \%)$, and $70.5 \%$ of research subjects had a job. Most of the risk factors for HIV-1 infection/transmission possibility were heterosexual (67.6\%). Co-infection was found in $22(21.0 \%)$ subjects, with the highest co-infection being hepatitis B. A total of 57 (55.3\%) subjects were at an advanced stage (stage 3 ).

The most common ARV regimens used by the study subjects were AZT+3TC+NVP (54.4\%) and TDF+3TC+EFV (40.8\%). Patients receiving second-line $A R V$ s were not found in this study.

A total of 105 proviral DNA isolates were amplified and electrophoresed, but only 17 samples showed clear bands. These 17 isolates (amplicons) were sequenced, but only eight RT sequences could be analyzed. The Stanford HIV database analysis found one DRM in the eight RT sequences (DRM prevalence = $12.5 \%)$, showing three new DRMs at the $184^{\text {th }}, 215^{\text {th }}$, and $190^{\text {th }}$ codon positions. These DRMs were M184L and T215N (DRMs for NRTI) with low-level resistance to AZT, and G190D (DRM for NNRTI), respectively.

Table 1. Demographic characteristics of research subjects $(n=105)$

\begin{tabular}{|c|c|}
\hline Characteristics & no. (\%) \\
\hline \multicolumn{2}{|l|}{ Gender: } \\
\hline - Male & $80(76.2)$ \\
\hline - Female & $25(23.8)$ \\
\hline \multicolumn{2}{|l|}{ Age, years old: } \\
\hline $20-29$ & $35(33.3)$ \\
\hline $30-39$ & $51(48.6)$ \\
\hline $40-49$ & $11(10.5)$ \\
\hline $50-59$ & $8(7.6)$ \\
\hline \multicolumn{2}{|l|}{ Marital status: } \\
\hline - Married & $55(52.4)$ \\
\hline - Single & $50(47.6)$ \\
\hline \multicolumn{2}{|l|}{ Education: } \\
\hline - SD (Elementary School) & $8(7.6)$ \\
\hline - SMP (Junior High School) & $19(18.1)$ \\
\hline - SMA (Senior High School) & $53(50.5)$ \\
\hline - College & $25(23.8)$ \\
\hline \multicolumn{2}{|l|}{ Job status: } \\
\hline - Working & $74(70.5)$ \\
\hline - Unemployment & $31(29.5)$ \\
\hline
\end{tabular}




\section{Discussion}

HIV-1 proviral DNA is a more stable genetic material than viral RNA and can be extracted from the buffy coat, whole blood, or peripheral blood mononuclear cells. HIV-1 proviral DNA also provides a greater probability of outcome against DRM analysis despite a low viral load $(<50$ copies $/ \mathrm{mL})$, due to the persistence of DRM in CD4 T cell memory [6, 7].

The success of the nested PCR and HIV-1 proviral DNA sequencing in this study was low, as only 17 samples showed bands on electrophoresis and the sequencing results showed only eight RT sequences that could be analyzed. Failure of the amplification of proviral HIV-1 DNA is most likely due to the high level of genetic variability of HIV-1, keeping the primer from sticking to the DNA template. The broad genetic variability of HIV-1 in different geographical regions of the world is caused by 1) error-prone RTinduced mutation, 2) recombination occurring during viral replication, 3) high rates of replication and viral turnover, and 4) diversification of viruses against immune selective pressure, including drug selective pressure due to long-term use of HAART [810].

Aghokeng et al. also reported changes in the success of several genotyping-based diagnostic methods due to the predominant genetic variation of HIV-1 sequences in Africa [11]. For instance, failure of the ViroSeq HIV-1 genotyping system amplified and interfered with some non-B variants in Cameroon that had high levels of HIV-1 variability. The use of degenerative primers is expected to amplify the success of proviral amplification of HIV-1 DNA.

Based on the results of this study, one DRM was obtained from eight isolates of RT, meaning that the prevalence of DRM was $12.5 \%$. Meanwhile, the other seven isolates of RT revealed the only variation of RT mutations that were unrelated to resistance to ARV. Data concerning DRM in Indonesia remain very limited. Khairunisa et al. conducted a DRM analysis of 66 HIV-1 patients who had used HAART for more than two years in Surabaya and found a $37.7 \%$ DRM prevalence. In contrast, Trotter et al. stated that the incidence of HIV DRMs in South and East Africa is estimated to have increased by $15 \%$ and $30 \%$ per year since HAART was first used [5].

DRM is based on rapid viral evolution and high levels of genetic variability in HIV-1 [1, 12-14]. Long-term ARV therapy results in drug selective immune pressure on the HIV-1 population, which causes mutations of viral peptides as the virus attempts to escape the host immune system. Viruses that escape the immune system are HIV-1 mutant strains, continuing the infection and replicating the host cells/CD4 T-cells to accumulate mutations suspected to cause DRM [1].

The DRMs found in this study were M184L and T215N (NRTI DRMs), and G190D (NNRTI DRM). Analysis of the Standford HIV database showed that the DRMs M184L and T215N elicited a low level of resistance to AZT in the subject while remaining sensitive to other NRTI classes. In contrast, the DRM G190D remained sensitive to all NNRTI groups. The DRMs of NRTIs at codons 184 and 215 observed in this study was also found in studies by Khairunisa et al. and Kotaki et al., but in both of those studies, the amino acid methionine was replaced by valine (M184V), not by leucine, and threonine was replaced by tyrosine (T215Y) and phenylalanine (T215F), not by asparagine (T215N) $[3,15]$. Mutations involving threonine are known as thymidine analog mutations (TAM). Based on the literature, other mutations in the
TAM position are often found; for example, the threonine at codon 215 (T215) can be replaced by amino acids other than phenylalanine $(\mathrm{F})$, such as tyrosine $(\mathrm{Y})$, cysteine $(\mathrm{C})$, aspartic acid $(D)$, glutamic acid $(E)$, isoleucine $(I)$, serine $(S)$, or valine $(V)$ (T215F/Y/C/D/E/I/S/V) [14]. In contrast, the current study found that threonine was replaced by asparagine (T215N). An NNRTI DRM at codon 190 was also found by Khairunisa et al., but in their study, the glycine in this position was replaced by alanine (G190A), not by aspartic acid (G190D). Kotaki et al. (2015) found no mutations in codon $190[3,15]$.

The novelty of this study's DRM results is also reinforced by previous data showing that $98.8-99.0 \%$ of HIV-infected persons on ARVs were found to possess specific M184V, K65R, K103N, V106M, Y181C, and G190A mutations [16, 17]. In contrast, the current study found a mutation at codon 184 where methionine was replaced by leucine (M184L), not by valine, and another mutation at codon 190 where glycine was replaced by aspartic acid (G190D), not by alanine.

In summary, the new DRMs found in Padang, West Sumatra indicates the importance of genotypic resistance testing and periodic evaluation of the effectiveness of ARV drugs currently in use. Further studies using greater sample sizes, as well as degenerative primers to improve amplification and sequencing success, are needed, however.

\section{Acknowledgments}

The authors would like to thank doctoral dissertation grant 2016 from the Directorate of Research and Community Service, Directorate General for Research and Development, Ministry of Research, Technology and Higher Education, Indonesia for funding this research.

\section{Conflict of interest}

We declare that we do not have any conflict of interest.

\section{References}

1. Gianella S, Richman DD. Minority variants of drug-resistant HIV. J Infect Dis 2010; 202(5): 657-666. https://doi.org/10.1086/655397.

2. Reynolds SJ, Sendagire H, Newell K, Castelnuovo B, Nankya I, Kamya $M$, et al. Virologic versus immunologic monitoring and the rate of accumulated genotypic resistance to first-line antiretroviral drugs in Uganda. BMC Infect Dis 2012; 12: 381. https://doi.org/10.1186/14712334-12-381.

3. Khairunisa $S Q$, Kotaki $T$, Witaningrum AM, Yunifiar $M Q$ Sukartiningrum SD, Nasronudin, et al. Appearance of drug resistanceassociated mutations in Human immunodeficiency virus type 1 protease and reverse transcriptase derived from drug-treated Indonesian patients. AIDS Res Hum Retroviruses 2015; 31(2): 255-259. https://doi.org/10.1089/AID.2014.0221.

4. Ditjen PP, Kemenkes PL. Statistik kasus HIV/AIDS di Indonesia. 2014.

5. Trotter AB, Hong SY, Srikantiah P, Abeyewickreme I, Bertagnolio S, Jordan MR. Systematic review of HIV drug resistance in the World Health Organization Southeast Asia Region. AIDS Rev 2013; 15(3): 162 170. https://www.ncbi.nlm.nih.gov/pubmed/24002200.

6. Lubke N, Di Cristanziano V, Sierra S, Knops E, Schulter E, Jensen B, et al. Proviral DNA as a target for HIV-1 resistance analysis. Intervirology. 2015; 58: 184-189. https://doi.org/10.1159/000431093.

7. Derache A, Shik Shin H, Balamane M, White E, Israelski D, Klausner JD, et al. HIV drug resistance mutations in proviral dna from a community treatment program. PLOS ONE 2015; 10(1): e0117430. https://doi.org/10.1371/journal.pone.0117430. 
8. Frankenberry KD, Galli A, Nikolaitchik O, Mens H, Pathak VK, Hu WS. Mechanisms and factors that influence high-frequency retroviral recombination. Viruses 2011; 3: 1650-1680. https://dx.doi.org/10.3390\%2Fv3091650.

9. Santoro MM, Perno CF. HIV-1 genetic variability and clinical implications. ISRN Microbiology 2013; 1: 20. http://dx.doi.org/10.1155/2013/481314.

10. Schlub TE, Smyth RP, Grimm AJ, Mak J, Davenport MP. Accurately measuring recombination between closely related HIV-1 genomes. PLoS Comput Biol 2010; 6(4): e1000766. https://doi.org/10.1371/journal.pcbi.1000766.

11. Aghokeng AF, Mpoudi-Ngole E, Chia JE, Edoul EM, Delaporte E, Peeters M. High failure rate of the ViroSeq HIV-1 genotyping system for drug resistance testing in Cameroon, a country with broad HIV-1 genetic diversity. J Clin Microbiol 2011; 49(4): 1635-1641. https://doi.org/10.1128/JCM.01478-10.

12. Arenas M. Genetic consequences of antiviral therapy on HIV-1. Computational and Mathematical Methods in Medicine 2015; 2015 : 395826. http://dx.doi.org/10.1155/2015/395826.

13. Clavel F. Mechanisms of HIV drug resistance: A primer. The PRN Notebook 2004; 9(1): 3-7.

14. Shafer RW, Schapiro JM. HIV-1 drug resistance mutations: an updated framework for the second decade of HAART. AIDS Rev 2008; 10(2): 6784. https://www.ncbi.nlm.nih.gov/pubmed/18615118.

15. Kotaki T, Khairunisa SQ, Witaningrum AM, Yunifiar MQ, Sukartiningrum SD, Diansyah $\mathrm{MN}$, et al. HIV-1 transmitted drug resistance mutations among antiretroviral therapy-Naïve individuals in Surabaya, Indonesia. AIDS Res Ther 2015; 12(5): 1-7. https://dx.doi.org/10.1186\%2Fs12981-015-0046-y.

16. Yon Rhee $S$, Jordan MR, Raizes E, Chua A, Parkin N, Kantor R., et al HIV-1 drug resistance mutation: Potential applications for point-ofcare genotypic resistance testing. PLOS ONE 2015; 10(12): e0145772. https://dx.doi.org/10.1371\%2Fjournal.pone.0145772.

17. Alteri C, Svicher V, Gori C, D'Arrigo R, Ciccozzi M, Ceccherini-Silberstein $\mathrm{F}$, et al. Characterization of the patterns of drug-resistance mutations in newly diagnosed HIV-1 infected patients naïve to the antiretroviral drugs. BMC Infect Dis 2009; 9: 111. https://doi.org/10.1186/14712334-9-111.

\section{Authors:}

Efrida Efrida - Clinical Pathologist, Lecturer, Department of Clinical Pathology, Faculty of Medicine, Andalas University, Padang, West Sumatera, Indonesia. http://orcid.org/0000-0002-6897-7921.

Ellyza Nasrul - Clinical Pathologist, Lecturer, Department of Clinical Pathology, Faculty of Medicine, Andalas University, Padang, West Sumatera, Indonesia. http://orcid.org/0000-0002-2370-2385.

Ida Parwati - Clinical Pathologist, Lecturer, Department of Clinical Pathology, Faculty of Medicine, Padjadjaran University, Bandung, West Java, Indonesia. http://orcid.org/0000-0002-9700-589X

Jamsari Jamsari - Lecturer, Departement of Agriculture, Andalas University, Padang, West Sumatera, Indonesia. http://orcid.org/00000002-6386-9120. 